\title{
DA PREVALÊNCIA DO VALOR DO TRABALHO HUMANO NA INTEGRAÇÃO DOS SISTEMAS PROCESSUAIS ${ }^{*}$
}

\author{
PREVALENCE OF VALUE OF WORK IN HUMAN \\ SYSTEMS INTEGRATION PROCEDURE
}

\author{
Kátia A. Pastori Terrin \\ Lourival José de Oliveira**
}

\begin{abstract}
Resumo: Diante do atual estágio de desenvolvimento do Processo Civil e da necessidade de se conferir aplicação da garantia constitucional da duração razoável do processo, os artigos 769 e 889 da CLT que tratam sobre a aplicação subsidiária do Direito Comum ao Processo do Trabalho, comportam interpretação conforme a Constituição Federal e principalmente diante dos princípios, permitindo a aplicação de normas processuais mais adequadas à efetivação do Direito. Assim sendo, o presente trabalho analisa a aplicação subsidiária de normas do Processo Comum ao Processo do Trabalho, mormente no que tange as recentes inovações trazidas pelas Leis 11.232/2005 e 11.280/2006, tendo como parâmetro a principiologia específica do Direito do Trabalho, bem como a valorização do trabalho humano. A abordagem faz-se de extrema necessidade e valia, principalmente na análise de omissões ontológicas e axiológicas, bem como na admissibilidade e aplicação dos princípios da Instrumentalidade, Celeridade, Efetividade, Proteção e Não-retrocesso social.
\end{abstract}

Palavras-chave: Subsidiariedade. Princípio. Processo do Trabalho. Processo Civil.

Abstract: In today's stage of development of Civil Procedure and the
need to check the applicability of the constitutional guarantee of a
reasonable duration of proceedings, the articles 769 and 889 of the Labor
Code, which provides for the subsidiary application of the Common Law
Procedure of Work, allow interpretation as the Federal Constitution and
especially on the principles, providing the application of procedural rules
more suited to the realization of the law. Therefore, this work intends to

Artigo oriundo da Dissertação de Mestrado defendida pela aluna Kátia Pastori Terrin, sob a orientação do Prof. Doutor Lourival José de Oliveira, no ano de 2010, na Universidade Estadual de Londrina, Paraná.

Mestre em Direito Negocial e Pós-graduanda em Direito Processual Civil e Direito Civil pela Universidade Estadual e Londrina; Professora do Curso de Direito da FACCAR. E-mail:katiaterrin@hotmail.com

"Doutor em Direito das Relações Sociais (PUC-SP); docente do Curso de Graduação em Direito e do Curso de Mestrado em Direito Negocial da Universidade Estadual de Londrina; docente do Curso de Mestrado em Direito da Unimar; Docente da FACCAR. E-mail: lourival.oliveira40@hotmail.com 
examine the scope of application as rules of procedure common to the labor process, especially concerning the recent innovations introduced by Law 11232/2005 and Law 11280/2006, limited to specific set of principles of Labor Law and the enhancement of human work. The approach is quite necessary, especially in dealing with ontological and axiological omissions, as well as eligibility and application of the Instrumentality, Speed, Effectiveness, Protection and Non-Social Regression Principles.

Key-words: Subsidiarity. Principle. Labor Procedure. Civil Procedure.

\section{INTRODUÇÃO}

A Consolidação das Leis do Trabalho estabelece o Direito Comum como fonte subsidiária do Direito Material e Processual do Trabalho, conforme se depreende da análise dos artigos 8o e 769, contudo, deve se ater a dois requisitos cumulativos, quais sejam, a omissão da legislação trabalhista e a compatibilidade com os preceitos do Direito do Trabalho.

A análise da compatibilidade se faz, em especial, no aspecto finalístico onde prevalece a valorização do trabalho humano. E é nesta celeuma que surgem os principais questionamentos e controvérsias que devem ser analisadas.

A aplicação subsidiária do Direito Processual Comum ao Processo do Trabalho suscita uma análise profunda ante o próprio substrato em questão. Diante de uma lide trabalhista, questões como a dignidade da pessoa humana, valores sociais do trabalho e ordem econômica do país, abarcam um cuidado especial por parte dos operadores do direito.

E é nesta celeuma jurídica que surgem as controvérsias oriundas do advento das Leis 11.232/2005 e 11.280/2006. Referidas alterações trazidas ao Código de Processo Civil brasileiro, acabam por refletir na própria dinâmica processual trabalhista.

Essas inovações suscitam dúvidas sobre a aplicabilidade ou não ao Processo do Trabalho, uma vez que, por uma análise principiológica, observam-se limites para a aplicação subsidiária de determinados institutos.

As alterações trazidas têm gerado inúmeras decisões controvertidas nos Tribunas brasileiros, não tendo ainda se firmado um posicionamento sólido sobre sua aplicação. O próprio Tribunal Superior do Trabalho ainda não se posicionou pacificamente, tendo havido divergências nos julgamentos pelas Turmas.

Embora divergentes, as variadas decisões e posicionamentos são respeitáveis e bem fundamentadas, o que de certa forma provoca certa insegurança jurídica. Principalmente diante do fato de que os efeitos dessas decisões repercutem sobremaneira no cenário jurídico e social. 
O assunto ainda é pouco explorado pela doutrina justrabalhista, que se mostra parca sobre o tema, motivo pelo qual se leva à necessidade de uma análise e estudo mais aprofundado a fim de se alcançar pilares de sustentação e aplicação efetiva.

O Direito Processual do Trabalho, como Direito autônomo que é, possui regramentos próprios, com peculiar origem histórica, bem como princípios e fontes específicas. Assim sendo, diante das inovações legislativas trazidas ao Código de Processo Civil brasileiro, nasce o questionamento com relação à aplicação prática desses institutos inovadores na ordem justrabalhista.

O tema desperta interesse pela importância do seu estudo em relação a um contexto maior, haja vista a necessidade de se aprofundar a interligação dos ramos do Direito, bem como despertar para uma hermenêutica jurídica, a fim de propiciar uma maior efetividade ao processo e, por conseguinte, alcançar a Justiça Social.

A repercussão de uma análise desse porte influencia diretamente na Ordem Econômica e Social do país, posto que reflete consequências práticas, oriundas das relações de trabalho, uma vez acionado o Poder Judiciário.

Além disso, tendo em vista o trabalho humano proporcionar individualidade ao cidadão, bem como inseri-lo no contexto social e econômico da sociedade, as questões jurídicas dele derivadas, necessitam de uma análise coerente com a ideologia proposta pelo Direito Constitucional e do Trabalho.

Tendo tido o Direito Processual do Trabalho sua gênese com os fatos sociais ocorridos na época da Revolução Industrial, ao se analisar as experiências de órgãos governamentais voltados à solução de litígios trabalhistas no Brasil, observa-se que a evolução do Direito do Trabalho se deu no sentido de firmar seus principais objetivos, mormente por meio dos princípios, que são as verdadeiras bases de sustentação da nova Ordem Jurídica emanada.

Somado a este contexto, a Carta Magna brasileira elegeu o primado do Trabalho como um dos fundamentos da Ordem Econômica e Social do país, reafirmando a real importância de se garantir uma maior proteção.

Nesse sentido, o Processo do Trabalho, como instrumento que serve ao Direito Material, torna-se um dos mecanismos de valorização do Trabalho Humano, na medida em que, conduzido de acordo com os princípios específicos da disciplina, operacionaliza a proposta social que o Direito do Trabalho abarca.

Busca-se, portanto, uma análise basilar, partindo-se da observância meticulosa dos princípios norteadores do Direito do Trabalho, dando ênfase ao estudo dos limites da aplicação subsidiária do Direito Processual Civil ao Processo do Trabalho. 
O presente estudo tem como escopo uma análise principiológica e integrativa dos dois sistemas processuais em questão, com vista a atender os objetivos perseguidos pelo Estado Democrático de Direito, em especial a prevalência do Valor Trabalho Humano como instrumento assegurador da Dignidade da Pessoa Humana, além de garantir a Ordem Econômica e Social da nação.

\section{O PROCESSO DO TRABALHO}

Dentro do estudo da Teoria Geral do Processo costuma-se analisar a distinção existente entre o Direito Material e o Processual, aquele tendo o papel de regular a vida das pessoas na sociedade, enquanto este visa regular a vida das partes dentro da relação processual.

Ao se abordar a necessidade de solução de conflitos, o que no Estado Moderno passou a ser majoritariamente uma atividade estatal, constata-se que os mesmos geram uma insegurança jurídica às partes, no sentido de que os autores sociais, ao se depararem com uma situação semelhante, não terão certeza de como agir, dado a dúvida sobre a interpretação ou correta aplicação da norma existente.

Se o direito visa a garantia da existência harmônica de uma dada sociedade, a existência de conflitos não resolvidos leva a uma situação em que os destinatários dessa mesma norma, que não os litigantes, incorrerão em dúvida sobre como proceder naquela situação, eis que os argumentos apresentados pelos litigantes serão sempre ponderáveis. E é aí, então, que "surge à necessidade de se decidir o conflito o quanto antes, minimizando os prejuízos que ele possa causar ao grupo social” (HINZ, 2007, p. 1448).

Tendo essa realidade fático-jurídica como pano de fundo, é possível arriscarse a uma interpretação das recentes alterações pelo qual vem passando o processo judicial pátrio nos últimos anos e tentar verificar qual o desafio trazido por tal tendência à sociedade como um todo e à comunidade jurídica em especial.

Porém, para que tal seja possível, deverá o profissional do direito não ser apenas um mero aplicador da norma, mas um cientista social, com conhecimentos básicos das realidades econômicas, sociológicas, psicológicas e antropológicas em relação ao momento histórico em que vive.

Assim, mais que uma visão interdisciplinar no sentido de capacitação de aplicação de diversos ramos do direito a uma mesma situação, insta que o profissional do direito possua conhecimento multidisciplinar, interligando e utilizando vários ramos do conhecimento, sempre tendo como norte as normas jurídicas e os princípios gerais do direito, adaptando novos valores aos anseios sociais.

Diante desta realidade, o Processo do Trabalho surge como um instrumento para a aplicação de normas jurídicas e princípios que reflitam valores sociais do 
trabalho. Tendo em vista que serve ao Direito Material do Trabalho, seu objetivo é justamente o de proporcionar uma prestação jurisdicional que atente aos seus fins.

Diante disso, a abordagem que aqui se inicia parte de uma análise atrelada aos fins sociais, econômicos, culturais, e por que não políticos, que o Direito do Trabalho brasileiro proporciona a sociedade democrática atual. Para tanto, o estudo da evolução histórica das relações de trabalho, bem como seus consecutivos se mostra essencial ao aprofundamento da questão.

\section{O PRINCÍPIO DA SUBSIDIARIEDADE E SUA FUNÇÃO INTEGRATIVA DOS SISTEMAS PROCESSUAIS}

O Direito Processual é um instrumento por meio do qual o Estado exerce a jurisdição com o objetivo de resolver conflitos mediante a aplicação da regra de Direito Material. A existência dessa base jurídica comum a qualquer ramo do Direito Processual "conduz a uma conseqüência teórica e a uma outra consequência prática” (LAURINO, 2005, p. 79-89).

A consequência teórica, concebido o Direito Processual como ramo autônomo da ciência jurídica, é a possibilidade de elaboração de uma Teoria Geral do Direito Processual, cujo objeto é o corpo de conhecimentos comuns a todos os ramos do Direito Processual, o que abrange os métodos, os princípios, os institutos e as funções sociais, políticas e jurídicas do sistema processual.

A consequência prática, concebido o Direito Processual como norma jurídica, é "a possibilidade de aplicação subsidiária de regras do Processo Comum como meio de integração das lacunas dos processos especiais. E se destaca no Processo do Trabalho ante a festejada simplicidade, que de certo é sua maior virtude, tem como contrapartida uma grande dependência do processo comum" (LAURINO, 2005).

Embora autônomo, o Direito Processual do Trabalho vale-se, subsidiariamente e de modo condicionado, das regras do Direito Processual Comum. As normas processuais trabalhistas são aplicadas com base num princípio fundamental, o princípio da subsidiariedade. Deve-se, contudo, ressaltar a importância da integração processual, mas sempre respeitando a autonomia do Direito Processual do Trabalho, já abordada em tópico específico.

A Consolidação das Leis do Trabalho estabelece que nos casos de omissão o Processo do Trabalho deve-se valer das regras do Direito Processual Comum, conforme previsão do artigo 769:

Art. 769 - Nos casos omissos, o direito processual comum será fonte subsidiária do direito processual do trabalho, exceto naquilo em que for incompatível com as normas deste Título (BRASIL, 1943). 
As grandes indagações que surgem no campo doutrinário são se o silêncio da Consolidação das Leis do Trabalho a respeito dos mais diferentes temas do processo configura lacuna; e em caso positivo, se os artigos 769 e 889 oferecem mecanismos de colmatação.

Sob a influência de um pensamento problemático, Aldhemar Prisco da Cunha Neto não vislumbra no silêncio legislativo da CLT, em primeiro plano, a hipótese de lacuna. Aponta, contudo, "a possibilidade de ser constatada posteriormente, mas para tanto, o juiz deve valer-se das normas subsidiariamente aplicáveis” (NETO, 2007, p. 1345).

Isso se torna compreensível na medida em que não se trabalha com a existência propriamente de um ordenamento jurídico processual do trabalho e outro ordenamento jurídico processual comum. E ao se reconhecer que integram o mesmo sistema jurídico, restará afastada a ideia de que a omissão da CLT equivale a lacuna, e que os artigos 769 e 889 estabeleçam critérios para sua completude.

Contudo, reafirma-se aqui "a autonomia do Direito Processual do Trabalho, que, dotado de peculiaridades, vasta matéria legislativa, princípios e regras próprias, traduz a ideia de um processo contemporâneo, na medida em que serve a um Direito Material também específico, propiciando ao cidadão não apenas o acesso à jurisdição, mas, sobretudo uma ordem justa” (LEITE, 2007, p. 36).

Reconhece-se, no entanto, que o Direito Processual do Trabalho não desfruta apenas de métodos tipicamente próprios, pois a hermenêutica, que compreende a interpretação, integração e aplicação das normas jurídicas processuais, é a mesma da Teoria Geral do Direito Processual.

Todavia, não se pode olvidar que a própria finalidade social deste direito processual específico exige do intérprete "uma postura comprometida com o Direito Material do Trabalho e com a realidade econômica e social, o que lhe impõe a adoção da técnica de interpretação teleológica, buscando sempre a verdade real e promovendo a Justiça Social no campo das relações decorrentes do conflito entre o capital e o trabalho" (LEITE, 2007, p. 85).

De um modo geral, o Direito Comum é, ainda, um direito individualista, diferentemente do Direito do Trabalho que pode ser dito como o vanguardeiro da socialização do Direito. Nasceu, justamente, da necessidade de corrigir as injustiças, ou desajustamentos, que a concepção individualista veio a provocar com o desenvolvimento da economia capitalista.

O Direito Processual do Trabalho é todo ele elaborado com o propósito da efetivação das normas de proteção ao trabalho, bem como de impedir que o litigante economicamente mais poderoso possa desviar ou retardar os fins da 
Justiça, mormente pelo fato de que no mais simples dissídio trabalhista estará sempre em jogo o maior dos problemas, que é a questão social.

O Processo do Trabalho não é mais apenas o instrumento de proteção dos direitos decorrentes da relação de trabalho, mas "o processo da Justiça do Trabalho", conforme a locução do artigo 763 da Consolidação (LAURINO, 2005, p. 79-89). Em razão disso, o exame da compatibilidade de normas do Processo Civil não poderá prescindir da consideração da natureza da relação jurídica de Direito Material a que se pede proteção perante a Justiça do Trabalho.

Autonomia do Direito Processual do Trabalho, contudo, não implica seu isolamento. Por integrar o sistema processual, deve observar a unidade metodológica comum a todos os demais ramos do direito processual.

Integrar tem o sentido de completar, inteirar, e no presente estudo reflete o suprimento das lacunas do sistema jurídico. Pode-se dizer, assim, que "a integração é o fenômeno que mantém a plenitude da ordem jurídica, ainda que inexistente norma jurídica específica a ser utilizada diante de determinado caso concreto a ser decidido” (LEITE, 2007, p. 93).

A integração constitui-se, portanto, de uma autorização do sistema jurídico para que o intérprete possa valer-se de certas técnicas para solucionar um caso concreto, no caso de lacuna.

A identidade do Processo do Trabalho decorre da necessidade de adequação ao objeto de sua proteção, que, a princípio, são os direitos substanciais tutelados pelo Direito do Trabalho. Em função disso, a aplicação subsidiária das normas do Processo Civil ao Processo do Trabalho depende do concurso dos dois requisitos exigidos pelo artigo 769 da Consolidação das Leis do Trabalho.

Entretanto, "o estudioso do Direito Processual deve estar consciente dos papéis reservados à lei e ao magistrado, admitindo que o julgador desempenhe uma atividade axiológica impregnada de valores, além de investigar a vontade da lei, sem, contudo, abandonar a exigência de conduzir o raciocínio secundum legem”. Portanto, nada excluiria do Direito Processual os temas ligados à boa interpretação, já que o juiz é "o intérprete da ordem jurídica positivada e a ele cabe atuar segundo regras processuais” (NETO, 2007, p. 1344).

A atividade do juiz persegue a efetividade através das regras processuais. Dentre elas, cumpre resgatar princípios constitucionais como o da razoável duração do processo (art. 5, LXXVIII) e o devido processo legal (art. 5o, LIV).

Assim, no esteio do que foi dito, mais prudente será confiar à lei a tarefa de oferecer o ferramental adequado para que o julgador possa cumprir o propósito de alcançar os resultados esperados no menor espaço de tempo possível, colhendo o que há de mais justo em seu conteúdo. E é claramente isso que se pretende com as diversas inovações trazidas pelo Código de Processo Civil. 
Para acolmatar as lacunas ontológicas e axiológicas do artigo 769 da CLT torna-se necessária uma visão hermenêutica que propicie um novo sentido ao seu conteúdo levando-se em conta o peso dos princípios.

A heterointegração deve pressupor a interpretação do artigo 769 da CLT não somente na hipótese tradicional de lacuna normativa do processo laboral, mas também quando a norma processual do trabalho se apresentar retrógada, impedindo ou dificultando a prestação jurisdicional justa e efetiva deste processo especializado.

No entanto, reforça-se a ideia de que no espaço jurídico - democrático atual não cabe ao Estado apenas garantir o acesso à tutela jurisdicional, mas sim proporcionar uma tutela de direitos que seja eficaz, efetiva e compatível com os anseios da sociedade, respeitando sempre a particularidade de cada relação.

E é nesse sentido que se faz cada vez mais necessária e útil a análise da aplicação das leis tendo por base a hermenêutica jurídica, mormente não que tange à interpretação da norma por meio dos princípios.

A interpretação consiste em uma ferramenta indispensável à boa compreensão da norma que compõe o ordenamento jurídico, tendo como alguns dos objetivos, o de "resguardar a Democracia Social ao levar em conta as condições sociais no momento da aplicação da norma” (ALVARENGA, 2009, p. 705).

É tarefa primordial do executor a pesquisa da relação entre o texto abstrato e o caso concreto, entre a norma jurídica e o fato social, isto é, aplicar o Direito. E para tanto, "deve-se descobrir e fixar o sentido verdadeiro da regra positiva, para então determinar seu alcance, sua extensão” (ALVARENGA, 2009, p. 705).

No Processo do Trabalho, ao se analisar a aplicação subsidiária do Código de Processo Civil, se torna indispensável o estudo dos princípios que regem o Direito Material e Processual do Trabalho, pois somente assim poder-se-á concluir pela compatibilidade das previsões contidas no referido Codex, superando assim as omissões existentes.

"O papel do intérprete contemporâneo consiste em um trabalho construtivo de natureza teleológica, calcado no confronto da norma com os princípios do Direito do Trabalho, aptos a valorar e a desenvolver a realização dos Direitos Humanos sociais do trabalhador". Assim, a interpretação no Direito do Trabalho deve reconstruir o conteúdo da norma de Direito Social, em nome da efetividade dos Direitos Humanos, pois à medida que a lei se afasta de sua finalidade, ela perde seu compromisso com o bem comum (ALVARENGA, 2009, p. 705).

Sendo o ordenamento jurídico brasileiro um sistema dinâmico, encharcado de ideologia valorativa, abarca o problema de saber se tem a possibilidade de qualificar normativamente todos os comportamentos possíveis, o que se 
sabe, não é o mais provável. Decorre daí, pois, a questão da completude ou incompletude dos sistemas normativos, mais especificamente das lacunas do ordenamento.

O intérprete deve estar atento aos princípios constitucionais do Direito do Trabalho, por meio de um processo hermenêutico - interpretativo que coadune pelo comprometimento dos direitos fundamentais sociais do trabalhador, além de buscar uma interpretação que compatibilize a norma com a realidade social brasileira (ALVARENGA, 2009, p. 705).

Portanto, o que se deve ressaltar é que a superação das lacunas no Processo do Trabalho não pode alterar sua estrutura, nem contrariar seus princípios informadores, mas deve ocorrer como forma de superação da ausência de regramento, aprimorando o procedimento trabalhista.

Para tanto, exige-se do intérprete e aplicador do direito "uma análise condizente com a totalidade do sistema existente para suprir tais lacunas e para atender ao objetivo fundamental da República Federativa do Brasil, conforme os ditames da Justiça Social e a plenitude dos fins sociais da norma" (ALVARENGA, 2009, p. 706).

Nesse sentido, a interpretação não deve confrontar os princípios fundamentais da Ordem Jurídica Democrática brasileira, consagradas nos artigos $1^{\circ}$ e $3^{\circ}$ da Constituição Federal de 1988, tais como a Dignidade da Pessoa Humana, Valores Sociais do Trabalho e da Livre Iniciativa, Cidadania, bem como construir uma Sociedade Justa e Solidária, primando pela promoção do bem de todos.

Portanto, a interpretação e aplicação do Direito do Trabalho devem levar em conta a exegese construtiva e valorativa das normas fundamentais justrabalhistas, para que se aperfeiçoem os fins teleológicos do Direito do Trabalho e os princípios basilares do Estado Democrático e Social de Direito.

Além de observar a realidade social do Brasil e os postulados constitucionais fundamentais encarnados na Constituição Federal de 1988, já que, na medida em que a norma fundamental justrabalhista se afasta de sua finalidade social original, perde o compromisso de conferir o bem estar social à coletividade.

\section{CONCLUSÃO}

As alterações legislativas sofridas pelo Código de Processo Civil têm por alvo, além de proporcionar maior efetividade, conferir racionalidade e celeridade à prestação jurisdicional, sem, contudo, ferir o direito ao contraditório e à ampla defesa, amoldando-o às exigências dos tempos modernos com suas transformações cada vez mais velozes e complexas das relações sociais e do trabalho. 
O Direito nasceu com o escopo de acompanhar as evoluções da sociedade a fim de regularizá-las. No entanto, esta tarefa se mostra praticamente impossível na velocidade com que as relações evoluem nos dias de hoje. Nasce então uma ferramenta singular aos operadores do direito que é a Heterointegração.

Integrar significa completar, inteirar, no sentido de suprir as lacunas dos sistemas jurídicos, resguardando a obrigatoriedade de o juiz dizer o direito e decidir o feito, procurando manter a plenitude da ordem jurídica (LEITE, 2007. p. 92).

"A integração autoriza ao intérprete valer-se de técnicas legais, tais como as fontes subsidiárias do direito, para solucionar um caso concreto, nos casos de lacuna" (LEITE, 2007. p. 93). E é neste diapasão que entra a figura dos princípios gerais do direito, que passam a funcionar muito além do que apenas fontes subsidiárias, mas como normas de introdução ao ordenamento jurídico brasileiro.

Ao se pensar a heterointegração dos subsistemas do Direito Processual Civil e do Direito Processual do Trabalho, faz-se necessário pensar um novo conceito de lacuna, e utilizar subsidiariamente as normas do Direito Processual Comum sempre que implicar maior efetividade ao Processo Laboral (LEITE, 2007. p. 93).

Ou seja, a integração dos sistemas reflete o próprio fim social e jurídico da norma, na medida em que busca dar maior agilidade e operacionalidade aos objetivos propostos pelo Direito.

Portanto, a Heterointegração, além da tradicional lacuna normativa, pressupõe lacunas ontológicas e axiológicas, que no caso em tela, encontra sua personificação no artigo 769 da Consolidação das Leis do Trabalho.

Portanto, exige-se cada vez mais a utilização da hermenêutica para o Direito, especialmente para o Direito do Trabalho, devendo o seu operador despir-se das propostas positivistas tradicionais e entrar na nova era do Direito, a era do Pós-Positivismo, onde os princípios auxiliam na interpretação e aplicação das normas às constantes transformações políticas, sociais e ideológicas.

E nada melhor do que se partir de um primado do valor "Trabalho Humano”, que transmite justamente a ideia de uma cristalização e necessidade de afirmação de condições de integração e desenvolvimento humano.

Resta clara a importância do operador, seja ele intérprete ou aplicador do Direito empregar a regra jurídica pautada nos anseios da sociedade, direcionado pela busca do bem comum e da Justiça Social, sendo o instrumento para tanto, o próprio Processo do Trabalho.

Somente neste caso, observando estes preceitos, poder-se-á finalmente conjugar a Ordem Econômica e Social com vistas ao desenvolvimento do país, para que então, se configure efetivamente um Estado Democrático de Direito. 


\section{REFERÊNCIAS}

ALMEIDA, Cleber Lúcio de. Princípios de Direito Processual do Trabalho. Revista LTr, São Paulo, v. 73, n. 2, p. 169-178, fev. 2009.

ALVARENGA, Rubia Zanotelli de. Hermenêutica jurídica e direitos humanos do trabalhador. Revista LTr, São Paulo, v. 73, n. 6, p. 705-718, jun. 2009.

AMARAL, Júlio Ricardo de Paula. Limitações à aplicação do princípio da proteção no direito do trabalho. Jus Navigandi, Teresina, ano 6, n. 51, 1 out. 2001. Disponível em: 〈http://jus.uol.com.br/revista/texto/2137〉. Acesso em: 25 fev. 2007.

BEBBER, Júlio Cesar. Reforma do CPC - Processo Sincrético e Repercussões no Processo do Trabalho. Revista LTr, São Paulo, v. 70, n. 2, p. 139-145, fev. 2006.

CESARINO JUNIOR, Antonio Ferreira. Tratado de direitos sociais brasileiro. São Paulo: Freitas Bastos, 1942.

CHAVES, Luciano Athayde. A recente reforma no processo comum: reflexos no Direito Judiciário do Trabalho. São Paulo: LTr, 2006.

DELGADO, Mauricio Godinho. Curso de Direito do Trabalho. 5. ed. São Paulo: LTr, 2006.

. Direitos fundamentais na relação de trabalho. Revista LTr, São Paulo, v. 70, n. 6, p. 657-667, jun. 2006.

- Princípios Constitucionais do Trabalho. Revista de Direito do Trabalho., São Paulo, v. 31, n. 117, p. 167-203, jan./mar. 2005.

GOMES, Dinaura Godinho Pimentel. Crise financeira e a valorização do trabalho humano. Revista LTr, São Paulo, v. 73, n. 2, p. 147-152, fev. 2009.

. Direito do trabalho e dignidade da pessoa humana, no contexto da globalização econômica. São Paulo: LTr, 2005.

HINZ, Henrique Macedo. Mudanças sociais e tendências do Direito Processual. Revista LTr, São Paulo, v. 71, n. 12, p. 1448-1452, dez. 2007.

LAURINO, Salvador Franco de Lima. Os reflexos das inovações do Código de Processo Civil no Processo do Trabalho. Revista do Tribunal Regional do Trabalho da 3ํRegião, Belo Horizonte, v. 1, n. 72, p. 79-89, jul./dez 2005.

LEITE, Carlos Henrique Bezerra. Curso de Direito Processual do Trabalho. 5. ed. São Paulo: LTr, 2007. 
MAIOR, Jorge Luiz Souto. Reflexos das alterações do Código de Processo Civil no processo do trabalho. Revista LTr, São Paulo, v. 70, n. 8, p. 920-930, ago. 2006. MALLET, Estevão. O processo do trabalho e as recentes modificações do Código de Processo Civil. Revista LTr, São Paulo, v. 70, n. 6, p. 668-675, jun. 2006.

Novas modificações no Código de Processo Civil e o processo do trabalho - Lei no 11.382/2006. Revista Magister: direito civil e processual civil, v. 3, n. 18, p. 5-31, maio/jun. 2007.

MELO, Raimundo Dimão de. Dignidade da pessoa humana e meio ambiente do trabalho. Revista de Direito do Trabalho, São Paulo, v. 31, n. 117, p. 204-220, jan./mar. 2005.

MENEZES, Cláudio Armando Couce de. Direito Processual do Trabalho: recentes alterações do CPC, temas atuais. São Paulo: LTr, 1996.

MORAES, Alexandre de. Constituição do Brasil interpretada e legislação constitucional. 2. ed. São Paulo: Atlas, 2003. Disponível em: <http://www. assediomoral.org/site/assedio/Amconceito.php>. Acesso em: 17 fev. 2007.

MOREIRA, José Carlos Barbosa. Efetividade do processo e técnica processual. Revista de Processo, São Paulo, v. 20, n. 77, p. 168-176, jan./mar. 1995.

NASCIMENTO, Amauri Mascaro. Curso de Direito Processual do Trabalho. São Paulo: Saraiva, 2002.

NETO, Adhemar Prisco da Cunha. Aspectos da aplicação do processo comum ao processo do trabalho. Revista LTr, São Paulo, v. 71, n. 11, p. 1340-1349, nov. 2007.

NETO, Francisco Ferreira Jorge; CALVACANTE, Jouberto de Quadros Pessoa. Direito Processual do Trabalho. 3. ed. Rio de Janeiro: Editora Lumem Juris, 2007. Tomo I.

RAMACCIOTTI, Júlio Cézar Lucchesi. A heterointegração e uma nova interpretação do art. 769 da Consolidação das Leis do Trabalho à luz do princípio da razoável duração do processo. Jus Navigandi, Teresina, ano 14, n. 2229, 8 ago. 2009. Disponível em: < http://jus.uol.com.br/revista/texto/13298>. Acesso em: 19 fev. 2010.

REALE, Miguel. Lições preliminares de Direito. 27. ed. São Paulo: Saraiva, 2010. SAKO, Emília Simeão Albino; HACKRADT, Hermann Araújo. A proteção 
jurídica dispensada aos direitos sociais - garantia assegurada por meio de cláusulas pétreas. Disponível em: 〈http://www.buscalegis.ufsc.br〉. Acesso em: 12 jan. 2010.

. Prescrição Ex Officio - $5^{\circ}$ do art. 219 do CPC - A Improbidade e a inadequação da alteração legislativa e sua incompatibilidade com o Direito e o Processo do Trabalho. Revista LTr, São Paulo, v. 70, n. 8, p. 966-973, ago. 2006.

SILVA, Bruno Freire e. A repercussão das reformas do Código de Processo Civil no Processo do Trabalho - Insegurança Jurídica. Revista LTr, São Paulo, v. 73, n. 1, p. 86-90, jan. 2009.

SILVA, José Antônio R. de Oliveira. As recentes alterações do CPC e sua aplicação no Processo do Trabalho. Revista LTr, São Paulo, v. 70, n. 12, p. 14839, dez. 2006.

SILVA, José Afonso da. Curso de Direito Constitucional. 16. ed. São Paulo: LTr, 1998.

SILVA, Paulo Tavarez da. A valorização do trabalho como Princípio Constitucional da Ordem Econômica Brasileira. Curitiba: Juruá, 2003.

SOUZA. Marcelo Papaléo de. Os Princípios Informadores do Processo de Execução Trabalhista e a Superação das Omissões da CLT. Revista LTr, São Paulo, v. 73, n. 7, p. 829-40, jul. 2009.

SCHIAVI, Mauro. Novas reflexões sobre a aplicação do art. 465-J do CPC ao Processo do Trabalho à Luz da Recente Jurisprudência do TST. Revista LTr, São Paulo, v. 72, n. 3,p. 271-6, mar. 2008.

SÜSSEKIND, Arnaldo; VIANNA Segadas; MARANHÃO, Délio; TEIXEIRA Lima. Instituições de direito do trabalho. 2. ed. atual. por Arnaldo Süssekind e João Teixeira Filho. São Paulo: LTr, 2004. v. 1.

Artigo recebido em 28/07/10 e aprovado para publicação em 06/09/10 
